\title{
Breastfeeding in relation to risk of different breast cancer characteristics
}

Salma Butt ${ }^{1,2^{*}}$, Signe Borgquist ${ }^{2,4}$, Lola Anagnostaki ${ }^{3}$, Göran Landberg ${ }^{3}$ and Jonas Manjer ${ }^{1,2}$

\begin{abstract}
Background: The aim of this present study was to examine duration of breastfeeding in relation to the risk of different subgroups of breast cancer. A prospective cohort, The Malmö Diet and Cancer study, including 14092 parous women, were followed during a mean of 10.2 years and a total of 424 incident breast cancers were diagnosed.

Methods: Tumours were classified regarding invasiveness, tumour size, axillary lymph node status, Nottingham grade, tumour proliferation (Ki67), HER2, cyclin D1 and p27, WHO histological type and hormone receptor status. Duration of breastfeeding was measured using total time of breastfeeding, categorized in quartiles using the lowest as the reference group ( $<4.0, \geq 4.0-<8.0, \geq 8.0-<13.0$ and $\geq 13.0$ months). Average duration of breastfeeding per child and breastfeeding duration of the first child were also used as exposures in separate analyses. Relative risks, with 95\% confidence intervals, were obtained using a Cox's proportional hazards analysis adjusted for potential confounders.

Results: Overall risk for breast cancer was similar in all quartiles of breastfeeding. No strong results regarding breastfeeding duration and breast cancer subgroups were seen. A few results indicated an association between a relatively long duration of breastfeeding and tumours with high proliferation (Ki67) and grade III histological grade.

Conclusions: Breastfeeding duration was not associated with breast cancer risk and no strong results were seen with regard to breast cancer subgroups.
\end{abstract}

Keywords: Breast cancer risk, Breastfeeding, Stage, Characteristics

\section{Background}

Several early studies and a recently a large meta-analysis including data from thirty countries, have shown a negative association between increasing time of breastfeeding and the risk of breast cancer [1]. However, a number of studies have not been able to shown this association as reviewed by Yang et al. [2]. One reason for these inconclusive findings may be that breastfeeding only influences the risk of certain sub-groups of breast cancer. There has been a limited number of studies investigating breastfeeding in relation to different breast cancer sub-groups, and only characteristics such as histological type and estrogen receptor status have been investigated [3-5].

In all, 17035 women participated in a prospective population-based cohort in Malmö, Sweden: The Malmö Diet and Cancer Study (MDCS). The MDCS collected

\footnotetext{
* Correspondence: salma.butt@med.lu.se

'Department of Surgery, Skåne University Hospital, Malmö, Lund University, Malmö, Sweden

${ }^{2}$ Malmö Diet and Cancer Study, Skåne University Hospital, Malmö, Sweden

Full list of author information is available at the end of the article
}

information on breastfeeding, as well as other reproductive and environmental factors. During follow-up, 622 women were diagnosed with breast cancer. Tumour tissue samples were available for about $90 \%$ of these women, which allowed tumour reclassification and further tumour biological examinations. Tumours were evaluated with regard to invasiveness, size, axillary lymph node status, Nottingham grade, tumour proliferation (Ki67), Human epidermal growth factor receptor 2 (HER2) status, and expression of cell cycle regulators such as cyclin D1 and p27. Tumours were further examined for WHO histological type (ductal, lobular, and tubular) and hormone receptor status; estrogen receptor alpha $(E R \alpha)$, estrogen receptor beta (ER $\beta)$ and progesterone receptor (PgR).

The aim of the present study was to examine breastfeeding in relation to the risk of breast tumours with different biological characteristics.

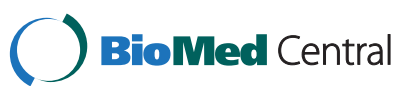

(c) 2014 Butt et al.; licensee BioMed Central Ltd. This is an Open Access article distributed under the terms of the Creative Commons Attribution License (http://creativecommons.org/licenses/by/2.0), which permits unrestricted use, distribution, and reproduction in any medium, provided the original work is properly credited. 


\section{Methods}

\section{The Malmö Diet and Cancer Study (The MDCS)}

All women born between 1923 and 1950 in Malmö were invited to a prospective cohort study, the MDCS. Between the years 1991 and 1996, 17035 women participated [6]. Written informed consent was obtained from all participants.

Information on breastfeeding, education, occupation, marital status, age at menarche, parity, year of each child's birth, age at menopause, exposure to oral contraceptives (OC) (ever/never), current use of hormonal replacement therapy (HRT), alcohol consumption and smoking habits were collected using a questionnaire at baseline [7].

Menopausal status was assessed using both medical records and the questionnaire. A women was considered postmenopausal: (1) if she had undergone bilateral oophorectomy; or (2) if she had undergone hysterectomy but not bilateral oophorectomy, and if she was $\geq 55$ years of age; or (3) if the above criteria were absent and she affirmed that her menstruations had ceased at least during the calendar year two years prior to baseline examination; or (4) if it was unknown whether or not she had undergone a previous oophorectomy or hysterectomy and information on menstrual status was missing, and she was $\geq 55$ years of age. In all 11388 women were postmenopausal at baseline. A woman was classified as pre-/perimenopausal if she affirmed that she was still menstruating, or if her menstruations had ceased less than two years prior to baseline examinations, or if information on menstrual status was missing and the women was $<55$ years of age at baseline.

Height and weight was measured at baseline by a trained nurse at the study centre, and Body Mass Index (BMI) was calculated as $\mathrm{kg} / \mathrm{m}^{2}$.

The MDCS and the present analyses were approved by the Ethical Committee at Lund University (LU 51-90 and Dnr 652/2005).

\section{Breastfeeding and parity}

Time of breastfeeding was assessed with the help of a questionnaire. All participants were asked to fill in the number of children they had given birth to. Information on birth years of the children and duration of breastfeeding was retrieved for the first seven children. No information on twin pregnancies was available. Parity was defined as the total number of children that a women answered she had given birth to.

Mean duration of breastfeeding per child was calculated as the sum of the months of breastfeeding divided by the number of children with information on breastfeeding.

Total time of breastfeeding was calculated as mean time of breastfeeding multiplied with parity. This calculation was made since time of breastfeeding was limited to seven children and a small amount of women had eight or more children $(n=13)$. Breastfeeding of the first child was investigated in an additional analysis, as it is likely that changes during the first pregnancy and following lactation period may be particularly important with regard to the differentiation of the breast tissue [8]. Women that had never breastfed were included in the lowest quartile in all breastfeeding groups.

\section{Follow-up}

All women were followed until 31 December 2004 with tumour end-points retrieved by record linkage with The Swedish Cancer Registry (until 31 December 2003). Due to a delay in central registration, linkage to its regional branch, The Southern Swedish Regional Tumour Registry, provided tumour-endpoints for the year 2004. Vital status was obtained from The Swedish Cause-of-Death Registry until 31 December 2004. A total of 622 incident breast cancer cases (including invasive and cancer in situ) were registered during follow-up.

\section{Study population}

Out of 17035 women, 576 had been diagnosed with breast cancer prior to inclusion in the study, and they were categorized as prevalent breast cancer cases and were subsequently excluded from the analyses. A total of 2089 women were nulliparous and hence excluded from the study population. Yet another 278 had no information on parity and were also excluded. This gave us a study population of 14092 women with 522 incident breast cancer cases. A total of 57, were cancer in situ (CIS) and only provided person-years until event, but did not provide invasive end-points in the analyses for "all breast cancers". CIS cases were neither included in the analyses of specific subgroups, e.g. histology and receptor status. Ten women with bilateral breast cancer were excluded as tumour end-points in the analyses due to difficulties in determining the relevant side to be used in the analyses of tumour size, axillary lymph nodes, histopathology and receptor status. A further 31 did not have sufficient tissue for further analyses. Bilateral cases and cases with no tumour material did however provide person-years up until the event. In all 424 tumours were included in the subgroup analyses (Figure 1).

\section{Histopathological analyses}

One senior breast pathologist re-evaluated all invasive tumours (LA). All tumours were re-evaluated concerning invasiveness and tumour type was described according to the WHO classification. The tumours were graded according to Elston and Ellis, including tubular formation, nuclear atypia and mitotic index [9]. Further tumour characteristics were evaluated using the tissue microarray technique (TMA). For the construction of tissue micro array, described elsewhere $[10,11]$ two cores of $0.6 \mathrm{~mm}$ from each tumour were taken and arranged in 


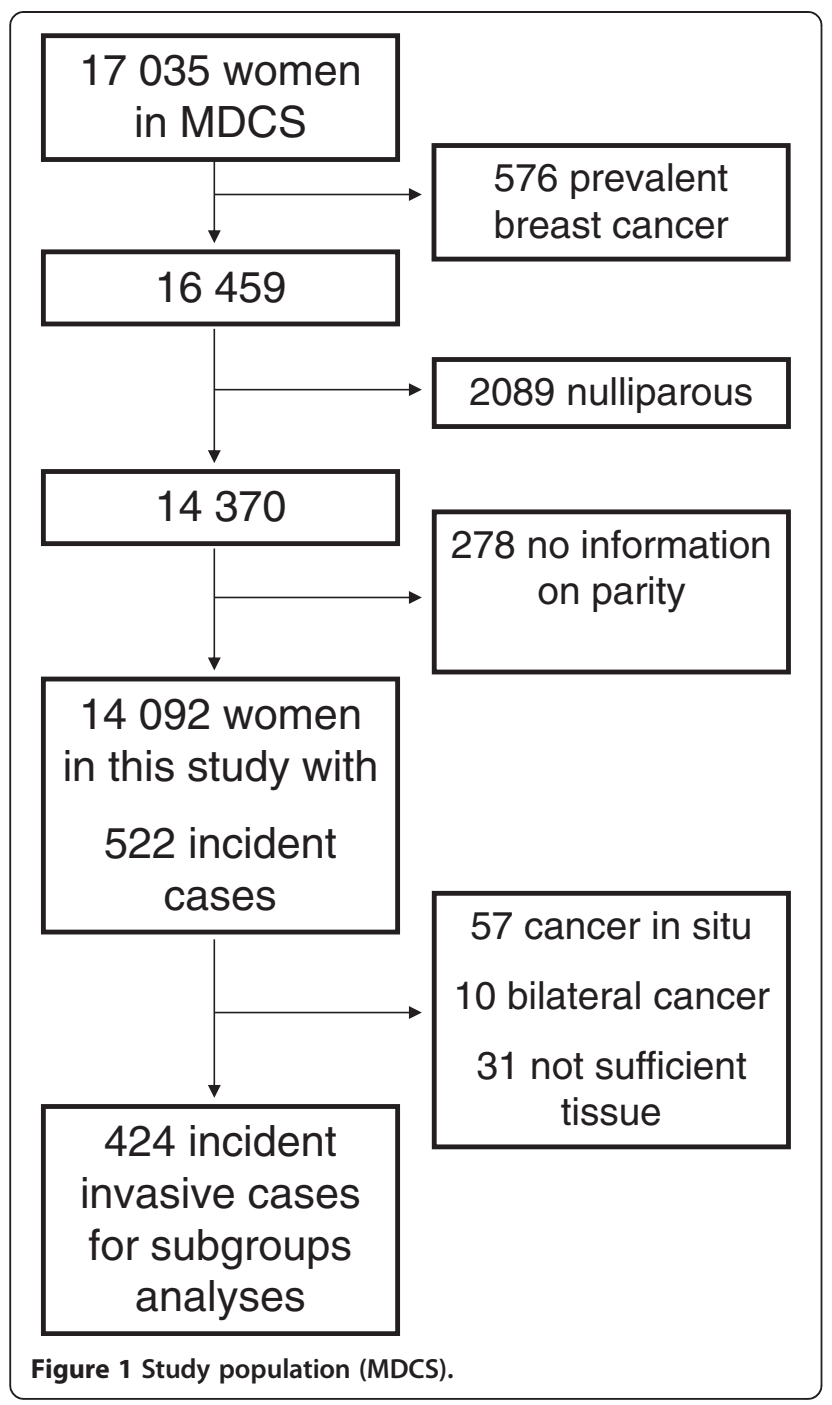

a recipient block. Immunohistochemical (IHC) analyses were performed using specific antibodies, described previously by Borgquist et al. [10] and tumours were evaluated according to the nucleus expression of ER $\alpha$, ER $\beta$, PgR, Ki67, cyclin D1 and p27. Tumours were dichotomized as negative and positive using the categories $0-10 \%$ and $11-100 \%$ of positive nuclei respectively. HER2 was analyzed using IHC as previously described [10]. HER2 was classified according to the Swedish clinical practice [12]. As data on HER2 amplification was not available, HER2 status was based on IHC analyses and in this study dichotomized into negative $(0$ and $1+)$ or positive cases $(2+$ and $3+)$. All arrays were evaluated independently twice by the same person $(\mathrm{SiB})$ and in case of discrepancy, a third evaluation was performed by the same investigator.

Information on tumour laterality, size and lymph node metastasis were retrieved from medical records and histopathological reports by one registered nurse.

\section{Statistical methods}

The main analyses used total duration of breastfeeding as measurements. Additional analyses used mean duration of breastfeeding and breastfeeding duration of the first child. Breastfeeding duration was divided into quartiles. Quartile cut-offs for breastfeeding were based on the distribution of all women in the study cohort. Different quartiles of breastfeeding were compared regarding the distribution of established and potential risk factors for breast cancer. Each subject was followed until the event of breast cancer, death or end of follow- up, 31 December 2004. The incidence of breast cancer was calculated per 100,000 person-years in different breastfeeding quartiles. Corresponding relative risks of breast cancer were analyzed using a Cox's proportional hazards analysis yielding relative risks (RR) with $95 \%$ confidence intervals (CI). These analyses were subsequently adjusted for potential confounders; age at baseline, education, socioeconomic status, marital status, age at menarche, age at first birth, parity, oophorectomy, age at menopause, oral contraceptive use, hormone replacement therapy use, bmi, alcohol consumption, smoking and height (categorized in Table 1).

Trend over breastfeeding categories was examined from the lowest to the highest quartile, excluding the missing category.

To examine heterogeneity, to test whether effect estimates were similar between for example grade I and grade III tumours in a certain breastfeeding quartile, adjusted case-case models using unconditional logistic regression analysis were used and p-values $<0.05$ were considered statistically significant.

\section{Results}

Total duration of breastfeeding in relation to risk factors for breast cancer

Women in the highest quartile of breastfeeding duration were more often multiparous and younger at first childbirth, as compared to all other groups. Moreover, women in the highest quartile were older at menopause, were less exposed to oral contraceptives and had to a higher extent never smoked (Table 1). All other factors were evenly distributed between breastfeeding categories.

\section{Total duration of breastfeeding in relation to risk of different breast cancer subgroups}

The overall risk of breast cancer (i.e. the risk of unilateral invasive tumours with biological material) was similar in all breastfeeding groups as compared to the lower quartile (Table 2). There was a trend towards grade III tumours in women with higher duration of breastfeeding, however this association did not reach statistical significance (Table 2). The risk of high Ki67 expressing tumours was statistically significantly associated with increased duration of breastfeeding (Table 3). Women in the lowest 
Table 1 Distribution of risk factors in different quartiles of total duration of breastfeeding

Time in months:

Total: 14092
$<4.0$

$n=2908$

$55.9(7.7)$

Mean (SD)

Education (n)

$$
\begin{aligned}
& \text { O-level college } \\
& \text { A-level college } \\
& \text { University }
\end{aligned}
$$

Type of occupation

Manual worker
Non-manual worker

Employer-self-employed

Married/cohabiting

$$
\begin{aligned}
& \text { No } \\
& \text { Yes }
\end{aligned}
$$

Age at menarche

$$
\begin{aligned}
& \leq 12 \\
& >12 \text { to }<15 \\
& \geq 15
\end{aligned}
$$

Parity

$$
\begin{gathered}
1 \\
2 \\
\geq 3
\end{gathered}
$$

Age at first childbirth

$$
\begin{aligned}
& \leq 20 \\
& >20 \text { to } \leq 25 \\
& >25 \text { to } \leq 30 \\
& >30
\end{aligned}
$$

Bilateral oophorectomy

$$
\begin{aligned}
& \text { No } \\
& \text { Yes }
\end{aligned}
$$

Age at menopause

$$
\begin{aligned}
& \text { Pre-/perimenopausal } \\
& \leq 45 \\
& >45 \text { to }<53 \\
& \geq 53
\end{aligned}
$$

Exposure to OC (ever/never)

$$
\text { Yes }
$$$$
\text { No }
$$

Exposure to HRT*

$$
\begin{aligned}
& \text { No } \\
& \text { ERT } \\
& \text { PRT }
\end{aligned}
$$$$
\text { CHRT }
$$

$\begin{array}{ll}74.0 & 72.7 \\ 7.7 & 6.7 \\ 18.3 & 20.4\end{array}$

72.7
6.7
20.4

20.4

40.7

39.3

52.9

7.1

$\geq 8.0-<13.0$

$\geq 13.0$

Missing

$\mathrm{n}=3484$

$n=3451$

$n=561$

Column percent (mean and SD in italics)

a

$\begin{array}{llll} & 57.6(7.7) & 58.5(8.1) & 57.7(6.7)\end{array}$

799.0

$\begin{array}{ccc}69.0 & 65.6 & 80.6 \\ 7.4 & 6.2 & 5.0 \\ 23.2 & 28.0 & 13.0\end{array}$

3.0

$\begin{array}{lll}52.9 & 53.6\end{array}$

$37.9-40.5$

45.6

53.6

49.7

47.1

7.5

8.3

5.5 
Table 1 Distribution of risk factors in different quartiles of total duration of breastfeeding (Continued)

\begin{tabular}{|c|c|c|c|c|c|}
\hline \multicolumn{6}{|l|}{ Height } \\
\hline Mean (SD) & $163.5(6.0)$ & $163.8(6.0)$ & $163.6(5.9)$ & $163.4(6.1)$ & $162.8(6.2)$ \\
\hline \multicolumn{6}{|l|}{ Body mass index } \\
\hline Mean (SD) & $25.5(4.4)$ & $25.3(4.5)$ & $25.3(4.2)$ & $25.7(4.4)$ & $26.0(4.8)$ \\
\hline \multicolumn{6}{|l|}{ Alcohol consumption } \\
\hline Nothing last year (teetotaler) & 10.9 & 9.2 & 10.3 & 13.8 & 17.5 \\
\hline Something last year (not last month) & 12.1 & 11.4 & 12.0 & 12.2 & 13.7 \\
\hline Something last month & 76.8 & 79.3 & 77.6 & 73.8 & 67.6 \\
\hline \multicolumn{6}{|l|}{ Smoking } \\
\hline Never & 38.2 & 40.6 & 45.4 & 49.9 & 44.4 \\
\hline Current & 33.2 & 30.6 & 26.5 & 23.0 & 33.9 \\
\hline Ex & 28.5 & 28.8 & 28.1 & 27.1 & 21.7 \\
\hline
\end{tabular}

Percentages do not always add up to $100 \%$ due to missing. ${ }^{*}$ Current in peri- and postmenopausal women $n=10288$.

breastfeeding quartile had a higher risk of expressing ductal type of breast tumour, however this results was not statistically significant (Table 4).

\section{Average duration of breastfeeding}

Women in the lowest quartile of average duration of breastfeeding were younger at baseline and were more often pre-/perimenopausal at breast cancer diagnosis as compared to all other groups (Additional file 1: Table S1). The relative risks for average duration of breastfeeding were similar to relative risks of total duration of breastfeeding. The risk of having grade III tumours were statistically significant for women in the highest quartile and the trend for having grade III tumours with increasing time of breastfeeding duration reached statistical significance (Additional file 1: Table S2). Moreover, no higher risk for tubular type was seen in any breastfeeding category (Additional file 1: Table S4).

\section{Breastfeeding duration of first child}

The analyses of breastfeeding of first child in relation to risk factors for breast cancer showed that women in the highest quartile were more likely to have had at later first childbirth as compared to the other breastfeeding groups. All other risk factors were distributed as for total duration of breastfeeding (Additional file 1: Table S5). All relative risks for breastfeeding of the first childbirth in relation to risk of different breast cancer subgroups were similar to those related to total duration of breastfeeding and average duration of breastfeeding (Additional file 1: Table S6-S8). There was a statistically significant increased risk of having high expression of cyclin D1 with increasing duration of breastfeeding (Additional file 1: Table S7).

\section{Discussion}

The aim of this study was to investigate breastfeeding in relation to the risk of different breast cancer subtypes and could not find any strong results. There was a trend towards more grade III tumours and high Ki67 expression with increasing duration of breastfeeding. However a lot of markers were tested and the quartile risks were not statistically significant for grade and Ki67 when studying total duration of breastfeeding.

\section{Methodological considerations}

Information on breastfeeding was retrieved from a questionnaire provided at baseline examinations where all women were 44 years or older, thus unlikely to have additional children following baseline. A previous study has confirmed self-reported breastfeeding to be highly accurate [13], hence we consider this information to be valid. A limitation of this study is that the questionnaire did not allow for a distinction between different breastfeeding patterns. That is, some women may have reported the time they were exclusively breastfeeding, whilst others may have filled in total duration of breastfeeding. There may also be secular trend in breastfeeding patterns, as the recommendations for exclusive/partial breastfeeding have changed over time in Sweden [14]. Today, Sweden is a country with high rate of women breastfeeding for at least six months [14], yielding a study population that is most likely affected by these patterns. There is still no established "best way" of defining the amount of breastfeeding. Most previous studies have used ever/ never breastfeeding as exposure. In the present study, there were 680 women (4.8\%) who reported that they had never breastfed. When the present data was re-analyzed using this categorization, there was no statistically significant association between overall breast cancer risk and ever breastfeeding (adjusted relative risk $=1.14$ : 0.70-1.88) as compared to never. Indeed, we consider it more valuable to investigate total time of breastfeeding in relation to different breast cancer characteristics in order to see if there was a threshold. 
Table 2 Risk of breast cancer subgroups defined by clinico-pathological markers in relation to total duration of breastfeeding

\begin{tabular}{|c|c|c|c|c|c|}
\hline Tumour subgroup & Breastfeeding total in months & Number of cases & Incidence/100000 & RR & $\mathrm{RR}^{*}$ \\
\hline \multicolumn{6}{|l|}{ Invasive } \\
\hline \multirow[t]{6}{*}{ breast cancer** } & $<4.0$ & 80 & 270 & 1.00 & 1.00 \\
\hline & $\geq 4.0-<8.0$ & 108 & 288 & $1.07(0.80-1.42)$ & $1.04(0.77-1.40)$ \\
\hline & $\geq 8.0-<13.0$ & 109 & 304 & $1.12(0.84-1.49)$ & $1.09(0.80-1.48)$ \\
\hline & $\geq 13.0$ & 103 & 293 & $1.08(0.81-1.45)$ & $1.10(0.78-1.54)$ \\
\hline & Missing & 24 & 399 & - & - \\
\hline & Total & 424 & 294 & p-trend: 0.56 & p-trend:0.45 \\
\hline \multicolumn{6}{|l|}{$\mathrm{CIS}$} \\
\hline & $<4.0$ & 9 & 30 & 1.00 & 1.00 \\
\hline & $\geq 4.0-<8.0$ & 19 & 51 & $1.67(0.76-3.70)$ & $1.90(0.84-4.30)$ \\
\hline & $\geq 8.0-<13.0$ & 13 & 36 & $1.20(0.51-2.81)$ & $1.40(0.57-3.46)$ \\
\hline & $\geq 13.0$ & 13 & 37 & $1.22(0.52-2.86)$ & $1.59(0.60-4.21)$ \\
\hline & Missing & 3 & 50 & - & - \\
\hline & Total & 57 & 40 & p-trend:0.98 & p-trend:0.48 \\
\hline \multicolumn{6}{|l|}{ Size $\leq 20 \mathrm{~mm}^{\#}$} \\
\hline & $<4.0$ & 55 & 186 & 1. 00 & 1.00 \\
\hline & $\geq 4.0-<8.0$ & 80 & 214 & $1.15(0.82-1.62)$ & $1.12(0.79-1.60)$ \\
\hline & $\geq 8.0-<13.0$ & 69 & 192 & $1.03(0.72-1.47)$ & $0.99(0.68-1.45)$ \\
\hline & $\geq 13.0$ & 85 & 241 & $1.30(0.93-1.82)$ & $1.29(0.87-1.92)$ \\
\hline & Missing & 15 & 249 & - & - \\
\hline & Total & 304 & 211 & $p$-trend:0.21 & p-trend:0.24 \\
\hline \multicolumn{6}{|l|}{ Size $>20 \mathrm{~mm}$} \\
\hline & $<4.0$ & 25 & 84 & 1.00 & 1.00 \\
\hline & $\geq 4.0-<8.0$ & 27 & 72 & $0.85(0.50-1.47)$ & $0.84(0.48-1.47)$ \\
\hline & $\geq 8.0-<13.0$ & 39 & 109 & $1.28(0.78-2.12)$ & $1.28(0.75-2.20)$ \\
\hline & $\geq 13.0$ & 18 & 51 & $0.61(0.33-1.11)$ & $0.65(0.33-1.27)$ \\
\hline & Missing & 9 & 150 & - & - \\
\hline & Total & 118 & 82 & p-trend:0.36 & p-trend:0.63 \\
\hline \multicolumn{6}{|l|}{ Axillary lymph } \\
\hline \multirow[t]{6}{*}{ node neg" } & $<4.0$ & 27 & 91 & 1.00 & 1.00 \\
\hline & $\geq 4.0-<8.0$ & 32 & 85 & $0.94(0.56-1.56)$ & $0.91(0.54-1.54)$ \\
\hline & $\geq 8.0-<13.0$ & 34 & 95 & $1.04(0.63-1.72)$ & $0.99(0.56-1.70)$ \\
\hline & $\geq 13.0$ & 31 & 88 & $0.97(0.58-1.62)$ & $0.90(0.50-1.64)$ \\
\hline & Missing & 5 & 83 & - & - \\
\hline & Total & 129 & 89 & p-trend:0.99 & $p$-trend:0.82 \\
\hline \multicolumn{6}{|l|}{ Axillary lymph } \\
\hline \multirow[t]{6}{*}{ node pos } & $<4.0$ & 53 & 179 & 1.00 & 1.00 \\
\hline & $\geq 4.0-<8.0$ & 72 & 192 & $1.07(0.75-1.53)$ & $1.05(0.73-1.51)$ \\
\hline & $\geq 8.0-<13.0$ & 71 & 198 & $1.10(0.77-1.57)$ & $1.08(0.73-1.57)$ \\
\hline & $\geq 13.0$ & 71 & 202 & $1.13(0.79-1.61)$ & $1.18(0.78-1.79)$ \\
\hline & Missing & 19 & 316 & - & - \\
\hline & Total & 286 & 198 & p-trend: 0.52 & $p$-trend:0.30 \\
\hline
\end{tabular}


Table 2 Risk of breast cancer subgroups defined by clinico-pathological markers in relation to total duration of breastfeeding (Continued)

\begin{tabular}{|c|c|c|c|c|c|}
\hline \multicolumn{6}{|l|}{ Grade I $^{\#}$} \\
\hline & $<4.0$ & 27 & 91 & 1.00 & 1.00 \\
\hline & $\geq 4.0-<8.0$ & 37 & 99 & $1.08(0.66-1.78)$ & $1.01(0.61-1.69)$ \\
\hline & $\geq 8.0-<13.0$ & 28 & 78 & $0.85(0.50-1.45)$ & $0.78(0.44-1.38)$ \\
\hline & $\geq 13.0$ & 28 & 80 & $0.87(0.51-1.48)$ & $0.87(0.47-1.61)$ \\
\hline & Missing & 7 & 116 & - & - \\
\hline & Total & 127 & 88 & p-trend:0.42 & p-trend:0.71 \\
\hline \multicolumn{6}{|l|}{ Grade II } \\
\hline & $<4.0$ & 33 & 111 & 1.00 & 1.00 \\
\hline & $\geq 4.0-<8.0$ & 47 & 125 & $1.12(0.72-1.75)$ & $1.05(0.67-1.66)$ \\
\hline & $\geq 8.0-<13.0$ & 53 & 148 & $1.32(0.85-2.03)$ & $1.15(0.73-1.83)$ \\
\hline & $\geq 13.0$ & 46 & 131 & $1.17(0.75-1.83)$ & $0.99(0.60-1.64)$ \\
\hline & Missing & 12 & 199 & - & - \\
\hline & Total & 191 & 132 & $p$-trend:0.40 & p-trend:0.97 \\
\hline \multicolumn{6}{|c|}{ Grade $\|^{\# \#}$} \\
\hline & $<4.0$ & 20 & 67 & 1.00 & 1.00 \\
\hline & $\geq 4.0-<8.0$ & 23 & 61 & $0.91(0.45-1.66)$ & $1.00(0.54-1.85)$ \\
\hline & $\geq 8.0-<13.0$ & 28 & 78 & $1.15(0.65-2.05)$ & $1.43(0.77-2.66)$ \\
\hline & $\geq 13.0$ & 29 & 82 & $1.22(0.69-2.16)$ & $1.74(0.89-3.41)$ \\
\hline & Missing & 5 & 83 & - & - \\
\hline & Total & 105 & 73 & p-trend:0.34 & $p$-trend:0.051 \\
\hline
\end{tabular}

*Adjusted for age at baseline (continuous), education, socioeconomic status, marital status, age at menarche, age at first birth, parity, oophorectomy, age at menopause, oral contraceptive use, hormone replacement therapy use, bmi, alcohol consumption, smoking and height.

**All cases with unilateral invasive breast cancer with tissue samples available for examination.

\#Reference group in heterogeneity analyses. "\# Heterogeneity: $p=0.031$.

All tumour endpoints were retrieved by record linkage to The Swedish Cancer Registry. This is a nation-wide registry and all cancer cases in Sweden are to be reported to this registry. This registry has previously been validated in Malmö and the completeness was 99\% regarding breast cancer [15].

Women with prevalent breast cancer were not included in the analyses since these women most likely are cause to bias. Women with a prevalent breast cancer at baseline are more likely to decline participation in a prospective study making them subject to selection bias. Moreover, a recent study has shown reduced lactation in these women [16].

The mammography screening program was fully initiated in Malmö 1990 and during 1991 - 1996 the average participation rate was $65 \%[17,18]$. This could have led to over diagnosis of breast cancer, but in our study only incident invasive breast cancers were included in the subgroup analyses. Further tumour classification with regard to the biomarkers, were analyzed using the TMA technique which is a well-documented method for tumour tissue screening and two cores are considered to be sufficient in order to get a representative sample $[19,20]$.
The IHC data was not retrieved in medical records since laboratory analyses were subject to changes over this period of time and hence analyzing all tumours again within TMAs by one pathologist was considered more accurate.

Women in the MDCS were probably selected towards higher socioeconomic groups and the participants in the MDCS had a higher incidence of breast cancer as compared to the rest of the female population in Malmö [6]. However, absolute risks may not be applicable to the background population, but, as we had a large variation in exposure within our sample, we consider that it is still possible to make internal comparisons, thus calculating valid relative risks.

In this study it is important to consider chance findings. There is a risk of a type I error due to the many analyses in this study and our previous study on parity and risk for different breast cancer subgroups was carried out in the same cohort MDCS [21]. No correction for multiple testing was made. As for type II errors, due to few individuals in some analyses, the confidence intervals were wide and the statistical power was relatively low which may have lead to a type II error in some comparisons. And it is 
Table 3 Risk of breast cancer subgroups defined by immunohistochemical markers in relation to total duration of breastfeeding

\begin{tabular}{|c|c|c|c|c|c|}
\hline Tumour subgroup & Breastfeeding total in months & Number of cases & Incidence/100000 & $\mathbf{R R}$ & $\mathrm{RR}^{*}$ \\
\hline \multicolumn{6}{|l|}{ Ki67 low } \\
\hline \multirow[t]{6}{*}{$(\leq 10 \%)^{\#}$} & $<4.0$ & 54 & 182 & 1.00 & 1.00 \\
\hline & $\geq 4.0-<8.0$ & 76 & 203 & $1.11(0.78-1.57)$ & $1.06(0.74-1.51)$ \\
\hline & $\geq 8.0-<13.0$ & 72 & 201 & $1.09(0.77-1.56)$ & $1.01(0.69-1.47)$ \\
\hline & $\geq 13.0$ & 58 & 165 & $0.90(0.62-1.31)$ & $0.82(0.53-1.25)$ \\
\hline & Missing & 11 & 183 & - & - \\
\hline & Total & 271 & 188 & $p$-trend:0.54 & p-trend:0.44 \\
\hline \multicolumn{6}{|l|}{ Ki67 high } \\
\hline \multirow[t]{6}{*}{$(>10 \%)$} & $<4.0$ & 17 & 57 & 1.00 & 1.00 \\
\hline & $\geq 4.0-<8.0$ & 21 & 56 & $0.98(0.51-1.85)$ & $1.02(0.53-1.96)$ \\
\hline & $\geq 8.0-<13.0$ & 26 & 72 & $1.25(0.68-2.31)$ & $1.39(0.72-2.67)$ \\
\hline & $\geq 13.0$ & 30 & 85 & $1.48(0.82-2.69)$ & $1.88(0.94-3.76)$ \\
\hline & Missing & 7 & 116 & - & - \\
\hline & Total & 101 & 70 & p-trend:0.11 & p-trend:0.03 \\
\hline \multicolumn{6}{|l|}{ HER2 $(0-1+)^{\#}$} \\
\hline & $<4.0$ & 57 & 192 & 1.00 & 1.00 \\
\hline & $\geq 4.0-<8.0$ & 78 & 208 & $1.08(0.77-1.52)$ & $1.02(0.72-1.45)$ \\
\hline & $\geq 8.0-<13.0$ & 84 & 234 & $1.21(0.86-1.69)$ & $1.12(0.78-1.61)$ \\
\hline & $\geq 13.0$ & 73 & 207 & $1.07(0.76-1.52)$ & $1.07(0.72-1.59)$ \\
\hline & Missing & 19 & 499 & - & - \\
\hline & Total & 311 & 216 & p-trend:0.58 & p-trend:0.44 \\
\hline \multicolumn{6}{|l|}{ HER2 $(2+-3+)$} \\
\hline & $<4.0$ & 9 & 30 & 1.00 & 1.00 \\
\hline & $\geq 4.0-<8.0$ & 9 & 24 & $0.80(0.32-2.01)$ & $1.02(0.39-2.65)$ \\
\hline & $\geq 8.0-<13.0$ & 11 & 31 & $1.02(0.42-2.46)$ & $1.40(0.53-3.69)$ \\
\hline & $\geq 13.0$ & 11 & 31 & $1.03(0.43-2.49)$ & $1.35(0.46-3.97)$ \\
\hline & Missing & 1 & 17 & - & - \\
\hline & Total & 41 & 28 & p-trend:0.79 & p-trend:0.59 \\
\hline \multicolumn{6}{|l|}{ Cyclin D1 low } \\
\hline \multirow[t]{6}{*}{$(\leq 10 \%)^{\#}$} & $<4.0$ & 54 & 182 & 1.00 & 1.00 \\
\hline & $\geq 4.0-<8.0$ & 82 & 219 & $1.20(0.85-1.69)$ & $1.15(0.81-1.64)$ \\
\hline & $\geq 8.0-<13.0$ & 73 & 203 & $1.11(0.78-1.58)$ & $1.05(0.72-1.53)$ \\
\hline & $\geq 13.0$ & 73 & 122 & $1.14(0.80-1.62)$ & $1.06(0.71-1.60)$ \\
\hline & Missing & 13 & 216 & - & - \\
\hline & Total & 295 & 205 & $p$-trend:0.65 & p-trend:0.77 \\
\hline \multicolumn{6}{|l|}{ Cyclin D1 high } \\
\hline \multirow[t]{6}{*}{$(>10 \%)$} & $<4.0$ & 14 & 47 & 1.00 & 1.00 \\
\hline & $\geq 4.0-<8.0$ & 14 & 37 & $0.79(0.37-1.65)$ & $0.84(0.39-1.78)$ \\
\hline & $\geq 8.0-<13.0$ & 24 & 67 & $1.38(0.72-2.68)$ & $1.56(0.77-3.19)$ \\
\hline & $\geq 13.0$ & 20 & 57 & $1.19(0.60-2.36)$ & $1.61(0.73-3.56)$ \\
\hline & Missing & 6 & 100 & - & - \\
\hline & Total & 78 & 54 & p-trend:0.29 & $p$-trend:0.10 \\
\hline
\end{tabular}


Table 3 Risk of breast cancer subgroups defined by immunohistochemical markers in relation to total duration of breastfeeding (Continued)

\begin{tabular}{|c|c|c|c|c|c|}
\hline \multicolumn{6}{|l|}{ P27 low } \\
\hline \multirow[t]{6}{*}{$(\leq 10 \%))^{\#}$} & $<4.0$ & 21 & 71 & 1.00 & 1.00 \\
\hline & $\geq 4.0-<8.0$ & 41 & 109 & $1.55(0.91-2.62)$ & $1.56(0.91-2.67)$ \\
\hline & $\geq 8.0-<13.0$ & 31 & 86 & $1.22(0.70-2.12)$ & $1.21(0.68-2.18)$ \\
\hline & $\geq 13.0$ & 35 & 99 & $1.40(0.82-2.41)$ & $1.35(0.73-2.50)$ \\
\hline & Missing & 7 & 116 & - & - \\
\hline & Total & 135 & 94 & p-trend:0.47 & p-trend:0.61 \\
\hline \multicolumn{6}{|l|}{ P27 high } \\
\hline \multirow[t]{6}{*}{$(>10 \%)$} & $<4.0$ & 48 & 162 & 1.00 & 1.00 \\
\hline & $\geq 4.0-<8.0$ & 53 & 141 & $0.87(0.59-1.29)$ & $0.83(0.55-1.24)$ \\
\hline & $\geq 8.0-<13.0$ & 65 & 181 & $1.11(0.76-1.61)$ & $1.04(0.70-1.56)$ \\
\hline & $\geq 13.0$ & 53 & 151 & $0.93(0.63-1.37)$ & $0.93(0.59-1.46)$ \\
\hline & Missing & 11 & 183 & - & - \\
\hline & Total & 230 & 159 & p-trend:0.95 & p-trend:0.73 \\
\hline
\end{tabular}

*Adjusted for age at baseline (continuous), education, socioeconomic status, marital status, age at menarche, age at first birth, parity, oophorectomy, age at menopause, oral contraceptive use, hormone replacement therapy use, bmi, alcohol consumption, smoking and height.

\#Reference group in heterogeneity analyses.

important to consider confounding especially in the subgroup analyses, and socioeconomic status might have an impact on breastfeeding pattern. Thulier et al. have reviewed variables associated with breastfeeding and concluded that higher educated and married women, tend to breastfeed their children for longer periods [22]. The relationship between increased risk of unfavourable breast cancer characteristics and time of breastfeeding could be measure of the association between socioeconomic status and breast cancer subgroups. In the MDCS, there was information available on education, type of occupation and marital status/cohabiting and all multivariate analyses were adjusted for these possible confounders. Hence, socioeconomic status should not have affected the results of these analyses. It has previously been shown that women in lower socioeconomic classes have a lower attendance in mammography screening as compared to women in higher socioeconomic classes [17]. This could possibly lead to detection bias, as women in higher socioeconomic classes would more likely have their breast cancer detected earlier; hence more likely have breast cancer with less aggressive characteristics and this would lead to a spurious association between breastfeeding and less aggressive breast cancer tumours. As the results in the present study were in the opposite direction, it makes such an association/detection bias unlikely.

\section{Previous studies}

The breast cancer characteristics Ki67 and grade have to our knowledge not been investigated with regard to breastfeeding previously. Most previous studies on breastfeeding and breast cancer markers, have investigated histological type and hormone receptor status. One previous study found increasing total time of breastfeeding protective against ductal type of breast cancer [5] opposite the non-significant findings in our study. Ursin et al. found total duration of breastfeeding to be protective against ER + PR + and ER-PR- tumours [5], and yet another found breastfeeding for more than six months to be protective against triple-negative breast tumours [4]. These findings were not confirmed in this study.

\section{Potential explanations}

Breastfeeding reduces lifetime ovulatory menstrual cycles [23] i.e. reducing the impact of hormone levels present during normal menstrual cycles [24] and by specifically reducing the progesterone exposure [25]. This may explain the finding in previous studies of a reduced risk of breast cancer in women who had breastfed. It is possible to hypothesize that an environment with relatively low levels of estrogen/progesterone may develop certain kind of tumour sub-groups, i.e. hormone independent tumours which in most cases are prognostically unfavourable tumours. We could in this study there not find any statistically significant association between breastfeeding and ER- tumours. Moreover breastfeeding stimulate the production of prolactin, a hormone that has been reported to have tumour promoting effects [26]. The potential relation between breastfeeding, prolactin and breast cancer is, however complex. Even if prolactin levels are high during lactation, it has been reported that among non-lactating women, prolactin levels in blood are relatively low in women with a previous long 
Table 4 Risk of breast cancer subgroups defined by type and receptor status in relation to total duration of breastfeeding

\begin{tabular}{|c|c|c|c|c|c|}
\hline Tumour subgroup & Breastfeeding total in months & Number of cases & Incidence/100000 & RR & $\mathrm{RR}^{*}$ \\
\hline \multicolumn{6}{|l|}{ Ductal $^{\#}$} \\
\hline & $<4.0$ & 59 & 199 & 1.00 & 1.00 \\
\hline & $\geq 4.0-<8.0$ & 74 & 197 & $0.99(0.70-1.39)$ & $0.99(0.70-1.41)$ \\
\hline & $\geq 8.0-<13.0$ & 74 & 206 & $1.03(0.73-1.45)$ & $1.04(0.72-1.51)$ \\
\hline & $\geq 13.0$ & 79 & 224 & $1.12(0.80-1.58)$ & $1.20(0.81-1.78)$ \\
\hline & Missing & 12 & 199 & - & - \\
\hline & Total & 298 & 207 & p-trend:0.45 & p-trend:0.26 \\
\hline \multicolumn{6}{|l|}{ Lobular } \\
\hline & $<4.0$ & 15 & 51 & 1.00 & 1.00 \\
\hline & $\geq 4.0-<8.0$ & 21 & 56 & $1.11(0.57-2.15)$ & $0.95(0.48-1.88)$ \\
\hline & $\geq 8.0-<13.0$ & 23 & 64 & $1.27(0.66-2.43)$ & $1.02(0.51-2.04)$ \\
\hline & $\geq 13.0$ & 14 & 40 & $0.79(0.38-1.63)$ & $0.65(0.29-1.45)$ \\
\hline & Missing & 9 & 150 & - & - \\
\hline & Total & 82 & 57 & p-trend:0.63 & p-trend:0.44 \\
\hline
\end{tabular}

Tubular

$$
\begin{aligned}
& <4.0 \\
& \geq 4.0-<8.0 \\
& \geq 8.0-<13.0 \\
& \geq 13.0 \\
& \text { Missing } \\
& \text { Total }
\end{aligned}
$$

13
27
20
17
33
20

ERa neg $\leq 10 \%{ }^{\#}$

$$
\begin{aligned}
& <4.0 \\
& \geq 4.0-<8.0 \\
& \geq 8.0-<13.0 \\
& \geq 13.0 \\
& \text { Missing } \\
& \text { Total }
\end{aligned}
$$

$\begin{array}{cc}1.00 & 1.00 \\ 1.97(0.62-6.29) & 2.09(0.64-6.89) \\ 1.43(0.42-4.89) & 1.59(0.43-5.91) \\ 1.26(0.36-4.47) & 1.56(0.37-6.70) \\ - & - \\ \text { p-trend: } 1.00 & \text { p-trend:0.75 }\end{array}$

ERa pos $>10 \%$

$$
\begin{aligned}
& <4.0 \\
& \geq 4.0-<8.0 \\
& \geq 8.0-<13.0 \\
& \geq 13.0 \\
& \text { Missing } \\
& \text { Total }
\end{aligned}
$$

30
32
36
43
17
35

$\begin{array}{cc}1.00 & 1.00 \\ 1.05(0.44-2.50) & 1.16(0.48-2.83) \\ 1.18(0.50-2.75) & 1.38(0.55-3.47) \\ 1.40(0.61-3.19) & 1.61(0.60-4.35) \\ - & - \\ \text { p-trend:0.38 } & \text { p-trend:0.30 }\end{array}$

ERß neg $\leq 10 \%{ }^{\#}$

$$
\begin{aligned}
& <4.0 \\
& \geq 4.0-<8.0 \\
& \geq 8.0-<13.0 \\
& \geq 13.0 \\
& \text { Missing } \\
& \text { Total }
\end{aligned}
$$

61

\subsection{0}

$1.10(0.79-1.53)$

$1.19(0.86-1.64)$

$1.10(0.79-1.54)$

p-trend:0.52

1.00

$1.04(0.64-1.68)$

$1.26(0.79-2.01)$

$1.16(0.72-1.87)$

1.00

$1.06(0.75-1.48)$

$1.13(0.79-1.60)$

$1.09(0.75-1.61)$

p-trend:0.47

1.00

$1.04(0.63-1.70)$

$1.26(0.76-2.09)$

$1.20(0.69-2.09)$

p-trend:0.40

p-trend:0.32 
Table 4 Risk of breast cancer subgroups defined by type and receptor status in relation to total duration of breastfeeding (Continued)

ERß pos $>10 \%$

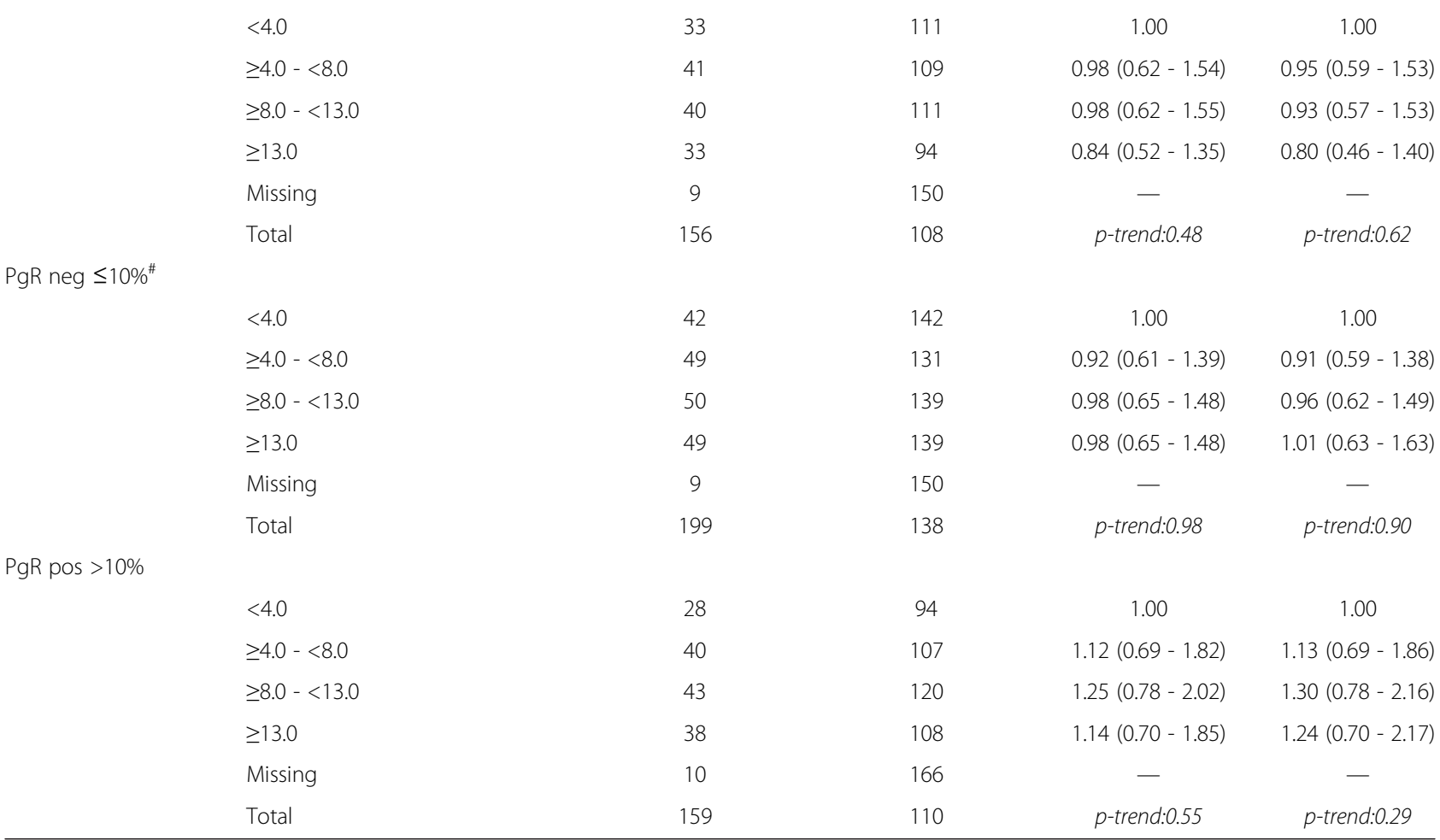

*Adjusted for age at baseline (continuous), education, socioeconomic status, marital status, age at menarche, age at first birth, parity, oophorectomy, age at menopause, oral contraceptive use, hormone replacement therapy use, bmi, alcohol consumption, smoking and height.

"Reference group in heterogeneity analyses.

duration of breastfeeding [27]. Moreover, breast tissue itself may be able to produce prolactin and this would probably lead to locally increased levels which are not detectable in ordinary blood samples [28]. The potential relationship between breast cancer subgroups and prolactin will however need to be studied in experimental studies, in order to investigate this further.

Generally, factors associated with an increased risk of breast cancer, e.g. HRT [10] and obesity [29] have been associated with prognostically relatively favorable breast tumours. Even if this study did not find any association of breastfeeding and reduced risk of breast cancer, it may be possible to hypothesize that the few associations between breastfeeding duration and aggressive breast cancer characteristics may reflect the same mechanism. It is possible to hypothesize that reproductive factors that are protective against breast cancer may also promote tumours that are non-hormone dependent and hence tumours that grow more autonomous. This should give rise to more aggressive characteristics when studying breast cancer subgroups with regard to reproductive factors as exposures. However, the biological mechanism behind this hypothesis has still to be identified.

\section{Conclusions}

Breastfeeding duration was not associated with breast cancer risk and no strong results were seen with regard to breast cancer subgroups.

\section{Availability of data}

This study was carried out in the Malmö Diet and Cancer Study (MDCS). In order to get access to the data, an application to the committee is needed. Please contact Prof. Jonas Manjer: jonas.manjer@med.lu.se.

\section{Additional file}

Additional file 1: Table S1. Distribution of risk factors in different
quartiles of average duration of breastfeeding. Table S2. Risk of breast cancer
subgroups defined by clinico-pathological markers in relation to average
duration of breastfeeding. Table S3. Risk of breast cancer subgroups defined by
immunohistochemical markers in relation to average duration of breastfeeding.
Table S4. Risk of breast cancer subgroups defined by type and receptor status
in relation to average duration of breastfeeding. Table S5. Distribution of risk
factors in different quartiles of breastfeeding duration of first child. Table S6.
Risk of breast cancer subgroups defined by clinico-pathological markers in
relation to breastfeeding duration of first child. Table S7. Risk of breast cancer
subgroups defined by immunohistochemical markers in relation to breastfeed-
ing duration of first child. Table S8. Risk of breast cancer subgroups defined
by type and receptor status in relation to breastfeeding duration of first child.




\section{Competing interests}

The authors declare that they have no conflict of interests.

\section{Authors' contributions}

SB participated in designing the study, carried out all the statistical analyses, participated in interpreting the results, reviewed the literature and drafted the manuscript. SiB participated in the study design, analyzing the tumours, interpreting the results and critically revised the manuscript. LA participated in the tumour analyses and critically revised the manuscript. GL participated in the study design, critically revised the results and the manuscript. JM designed the study, supervised and participated in analyzing all statistical analyses and critically revised the manuscript. All authors have read and given approval of the final manuscript.

\section{Acknowledgements}

Financial support was received from The Ernhold Lundström Foundation, The Einar and Inga Nilsson Foundation, The Malmö University Hospital Cancer Research Fund, The Malmö University Hospital Funds and Donations, The Crafoord Foundation, The Anna Lisa and Sven-Eric Lundgren Foundation, The Mossfelt Foundation, The Fröken Anna Jönssons Foundation and The Maja and Hjalmar Leanders Foundation. The authors would also like to thank Ms Else Nilsson for excellent technological work.

\section{Author details}

'Department of Surgery, Skåne University Hospital, Malmö, Lund University, Malmö, Sweden. 'Malmö Diet and Cancer Study, Skåne University Hospital, Malmö, Sweden. ${ }^{3}$ Centre for Molecular Pathology, Department of Laboratory Medicine, Skåne University Hospital, Malmö, Sweden. ${ }^{4}$ Division of Oncology, Department of Clinical Sciences, Skåne University Hospital, Lund, Sweden.

Received: 27 November 2012 Accepted: 21 March 2014

Published: 7 April 2014

\section{References}

1. Collaborative Group on Hormonal Factors in Breast Cancer: Breast cancer and breastfeeding: collaborative reanalysis of individual data from 47 epidemiological studies in 30 countries, including 50302 women with breast cancer and 96973 women without the disease. Lancet 2002, 360(9328):187-195.

2. Yang $L$, Jacobsen $\mathrm{KH}$ : A systematic review of the association between breastfeeding and breast cancer. J Womens Health (Larchmt) 2008, 17(10):1635-1645.

3. Ma H, Bernstein L, Pike MC, Ursin G: Reproductive factors and breast cancer risk according to joint estrogen and progesterone receptor status: a meta-analysis of epidemiological studies. Breast Cancer Res 2006, 8(4):R43.

4. Phipps Al, Malone KE, Porter PL, Daling JR, Li Cl: Reproductive and hormonal risk factors for postmenopausal luminal, HER-2-overexpressing, and triple-negative breast cancer. Cancer 2008, 113(7):1521-1526.

5. Ursin G, Bernstein L, Lord SJ, Karim R, Deapen D, Press MF, Daling JR, Norman SA, Liff JM, Marchbanks PA, Folger SG, Simon MS, Strom BL, Burkman RT, Weiss LK, Spirtas R: Reproductive factors and subtypes of breast cancer defined by hormone receptor and histology. $\mathrm{Br} J$ Cancer 2005, 93(3):364-371.

6. Manjer J, Carlsson S, Elmståhl S, Gullberg B, Janzon L, Lindström M, Mattisson I, Berglund G: The Malmo Diet and Cancer Study: representativity, cancer incidence and mortality in participants and non-participants. Eur J Cancer Prev 2001, 10(6):489-499.

7. Manjer J, Elmstahl S, Janzon L, Berglund G: Invitation to a population-based cohort study: differences between subjects recruited using various strategies. Scand J Public Health 2002, 30(2):103-112.

8. Russo J, Moral R, Balogh GA, Mailo D, Russo IH: The protective role of pregnancy in breast cancer. Breast Cancer Res 2005, 7(3):131-142

9. Elston CW, Ellis IO: Pathological prognostic factors in breast cancer. I. The value of histological grade in breast cancer: experience from a large study with long-term follow-up. Histopathology 1991, 19(5):403-410.

10. Borgquist S, Anagnostaki L, Jirstrom K, Landberg G, Manjer J: Breast tumours following combined hormone replacement therapy express favourable prognostic factors. Int J Cancer 2007, 120(10):2202-2207.

11. Borgquist S1, Wirfält E, Jirström K, Anagnostaki L, Gullberg B, Berglund G, Manjer J, Landberg G: Diet and body constitution in relation to subgroups of breast cancer defined by tumour grade, proliferation and key cell cycle regulators. Breast Cancer Res 2007, 9(1):R11.

12. Dowsett M, Bartlett J, Ellis IO, Salter J, Hills M, Mallon E, Watters AD, Cooke T, Paish C, Wencyk PM, Pinder SE: Correlation between immunohistochemistry (HercepTest) and fluorescence in situ hybridization (FISH) for HER-2 in 426 breast carcinomas from 37 centres. J Pathol 2003, 199(4):418-423.

13. Troy LM, Michels KB, Hunter DJ, Spiegelman D, Manson JE, Colditz GA, Stampfer MJ, Willett WC: Self-reported birthweight and history of having been breastfed among younger women: an assessment of validity. Int $J$ Epidemiol 1996, 25(1):122-127.

14. SoS (The National Board of Health and Welfare in Sweden): Breast-feeding, children born 2006. 2006: [http://www.socialstyrelsen.se/publikationer2008/ 2008-125-12]

15. Garne JP: Invasive breast cancer in Malmö 1961-1992 - an epidemiological study. Dissertation. Malmö: Lund University; 1996.

16. Leal SC, Stuart SR, Carvalho Hde A: Breast irradiation and lactation: a review. Expert Rev Anticancer Ther 2013, 13(2):159-164.

17. Matson S, Andersson I, Berglund G, Janzon L, Manjer J: Nonattendance in mammographic screening: a study of intraurban differences in Malmo, Sweden, 1990-1994. Cancer Detect Prev 2001, 25(2):132-137.

18. Zackrisson S, Andersson I, Manjer J, Janzon L: Non-attendance in breast cancer screening is associated with unfavourable socio-economic circumstances and advanced carcinoma. Int J Cancer 2004, 108(5):754-760.

19. Camp RL, Charette LA, Rimm DL: Validation of tissue microarray technology in breast carcinoma. Lab Invest 2000, 80(12):1943-1949.

20. Hoos A, Cordon-Cardo C: Tissue microarray profiling of cancer specimens and cell lines: opportunities and limitations. Lab Invest 2001, 81(10):1331-1338.

21. Butt S, Borgquist S, Anagnostaki L, Landberg G, Manjer J: Parity and age at first childbirth in relation to the risk of different breast cancer subgroups. Int J Cancer 2009, 125(8):1926-1934.

22. Thulier D, Mercer J: Variables associated with breastfeeding duration. J Obstet Gynecol Neonatal Nurs 2009, 38(3):259-268.

23. Russo J, Russo $\mathrm{H}$ : Toward a physiological approach to breast cancer prevention. Cancer Epidemiol Biomarkers Prev 1994, 3(4):353-364.

24. Bernstein L: Epidemiology of endocrine-related risk factors for breast cancer. J Mammary Gland Biol Neoplasia 2002, 7(1):3-15.

25. Henderson BE, Ross RK, Judd HL, Krailo MD, Pike MC: Do regular ovulatory cycles increase breast cancer risk? Cancer 1985, 56(5):1206-1208.

26. Tworoger SS, Hankinson SE: Prolactin and breast cancer risk. Cancer Lett 2006, 243(2):160-169.

27. Hietala M, Olsson $\mathrm{H}$, Jernstrom $\mathrm{H}$ : Prolactin levels, breast-feeding and milk production in a cohort of young healthy women from high-risk breast cancer families: implications for breast cancer risk. Fam Cancer 2008, 7(3):221-228.

28. Clevenger CV, Chang WP, Ngo W, Pasha TL, Montone KT, Tomaszewski JE: Expression of prolactin and prolactin receptor in human breast carcinoma. Evidence for an autocrine/paracrine loop. Am J Pathol 1995, 146(3):695-705.

29. Borgquist S, Jirstrom K, Anagnostaki L, Manjer J, Landberg G: Anthropometric factors in relation to different tumor biological subgroups of postmenopausal breast cancer. Int J Cancer 2009, 124(2):402-411.

\section{doi:10.1186/1756-0500-7-216}

Cite this article as: Butt et al:: Breastfeeding in relation to risk of different breast cancer characteristics. BMC Research Notes 2014 7:216.

\section{Submit your next manuscript to BioMed Central and take full advantage of:}

- Convenient online submission

- Thorough peer review

- No space constraints or color figure charges

- Immediate publication on acceptance

- Inclusion in PubMed, CAS, Scopus and Google Scholar

- Research which is freely available for redistribution 